\title{
Diagnosis and antiviral therapy of hepatitis B and D - Hungarian Consensus Guideline
}

\author{
Effective from 20 September 2019 until withdrawal
}

\begin{abstract}
| Gábor Horváth dr. , Zsuzsanna Gerlei dr. ${ }^{2}$, Judit Gervain dr. ${ }^{3}$, Gabriella Lengyel dr. ${ }^{4}$, Mihály Makara dr. ${ }^{5}$, Alajos Pár dr. , László Rókusz dr. ${ }^{7}$, Ferenc Szalay dr. ${ }^{8}$, István Tornai dr. ${ }^{9}$, Klára Werling dr. ${ }^{4}$, Béla Hunyady dr. ${ }^{10}$

${ }^{1}$ Hepatology Center of Buda, Budapest, Hungary; Hepatogy Outpatient Unit, Ist Department of Medicine, St. János Hospital and North Buda Integrated Hospitals, Budapest, Hungary; ${ }^{2}$ Department of Surgery and Transplantation Surgery, Semmelweis University, Faculty of Medicine, Budapest, Hungary; ${ }^{3}{ }^{\mathrm{st}}$ Department of Medicine and Laboratory of Molecular Diagnostics, St. György Hospital, Székesfehérvár, Hungary; ${ }^{4}{ }^{\text {nd }}$ Department of Internal Medicine, Semmelweis University, Faculty of Medicine, Budapest, Hungary; ${ }^{5}$ Hepatogy Outpatient Unit, Central Hospital of Southern Pest National Institute of Hematology and Infectious Diseases, Budapest, Hungary; ${ }^{6}{ }^{\text {nd }}$ Department of Medicine, University of Pécs, Pécs, Hungary; $\left.{ }^{7}\right|^{\text {st }}$ Department of Medicine, Medical Centre, Military Hospital Hungarian Defence Forces, Budapest, Hungary; $\left.{ }^{8}\right|^{\text {st }}$ Department of Internal Medicine, Semmelweis University, Faculty of Medicine, Budapest, Hungary; ' ${ }^{2}$ ivision of Gastroenterology, Department of Medicine, Faculty of Medicine, University of Debrecen, Hungary; ${ }^{10}$ Department of Gastroenterology, Somogy County Kaposi Mór Hospital, Kaposvár, Hungary; Ist Department of Medicine, University of Pécs, Pécs, Hungary

Correspondence: horvath.gabor@hepatologia.hu
\end{abstract}

Diagnosis and treatment of HBV \pm HDV infection means for the patient to be able to maintain working capacity, to increase quality of life, to prevent cancer, and to prolong life expectancy, while society benefits from eliminating the chances of further transmission of the viruses, and decreasing the incidence and overall costs of serious complications. The guidelines outline the treatment algorithms that have been in place since 2019 , developed at a consensus meeting of physicians involved in treating these diseases. The indications of treatment is based upon viral examinations (including viral nucleic acid determination) with determinations of disease activity and stage of related liver disease (by laboratory tests, pathologic, and/or non-invasive methods, i.e., elastographies or biochemical scores), and excluding contraindications. The first choices of therapy in chronic hepatitis B infection includes pegylated interferon for $\mathbf{4 8}$ weeks or continuous nucleotide/nucleoside analogue (NAs: entecavir or tenofovir). NAs must be continued for at least 12 months after hepatitis B surface antigen seroconversion. Some NAs are not available/not routinely used in Hungary. Lamivudine is no longer a first choice; patients currently taking lamivudine must switch if response is inadequate. Appropriate treatment of patients taking immunosuppressive medications is highly recommended. Pegylated interferon based therapy is recommended for the treatment of concomitant hepatitis D infection.

KEYWORDS: hepatitis B virus, hepatitis D virus, viral hepatitis, cirrhosis, liver cancer, interferon, pegylated interferon, lamivudine, adefovir, entecavir, tenofovir 


\section{Introduction}

Hepatitis B virus is a member of the hepadnavirus family with a circular DNA genome. Among adult patients, acute HBV infection becomes chronic in $<10 \%$ of cases. If the infection happens during the perinatal period, this rate is $>90 \%$. Chronic HBV infection usually causes asymptomatic infection for decades, during which, the patient can infect other people. However it can also cause chronic inflammation in the liver (CHB) and - by time - severe liver diseases (cirrhosis, liver cancer) which reduces the ability to work, the quality of life, and also the life expectancy. In addition, treatment of complications requires great cumulative costs from the healthcare system. HBV is a direct oncogene. Therefore every patient with chronic HBV infection has an increased risk of developing liver cancer even if the HBV infection doesn't cause any significant liver disease. The estimated seroprevalence of HBV infection ( $\mathrm{HBsAg}+)$ in Hungary is $0,3-0,5 \%$.

A new nomenclature of the five phases of the HBV infection was accepted by the EASL in 2017. Each phase is differentiated from the others on the basis of HBeAg status, degree of replication (HBV DNA), biochemical activity (GPT/ALT), and the inflammation in the tissues of the liver (if histology performed) (Table 1).

Hepatitis D (delta) virus contains RNA genome. It's a defective virus; its replication depends on the presence of HBV infection. Thus, it can infect only patients with HBV or it can be concomitant infection. In most cases, HDV infection causes more severe liver damage and/or faster progression of an existing disease (leading to cirrhosis) than HBV alone. HDV also means a higher risk of liver cancer.

Chronic HBV/HDV infections usually do not cause any symptoms. However, early diagnosis and treatment of the HBV/HDV infection are essential. From the patients' aspect: it helps the patient to maintain their ability to work, improves the quality of life, helps prevention of cancer, and extends the disease-free lifespan. From the aspect of the environment of the patient and also the society: it stops the transmission of the infection and reduces the costs of the healthcare system (because of the prevention of severe liver diseases). In Hungary, gastroenterologists, infectologists and tropical diseases specialists are assigned to manage HBV/HDV infections, according to consensus-based professional guideline (since 2006), updated annually to include new evidences, publications, international recommendations, approved labels of drugs and cost-benefit analysis (1, 2, 3, 4, 5). However, IFN-based therapies for HBV and HDV (just like therapies for HCV) are only authorized for specialists at designated Hepatitis Centers, under the supervision of a Hepatitis Therapy Committee (former: Interferon Committee, hereinafter referred to Committee; office: H-1092 Budapest Kinizsi u. 22., E-mail: gastroent@ gmail.com, web: www.gastroent.hu). Members of the Committee are delegated by professional organizations.

This current guideline is an updated version of the previous from 2017 (1). It was accepted on the $20^{\text {th }}$ of September, 2019. However, the latest financing protocol of NEAK (based on a previous professional guideline from

\section{Key recommendations}

A1. All patients with a high risk (including every patient with chronic liver disease) to be screened for HBV (HBsAg, anti-HBC). In high risk populations anti-HBs serology must also be performed if immunization history is incomplete or unknown.

A2. In case of HBV seronegativity, vaccination against $\mathrm{HBV}$ is indicated for all patients with chronic liver diseases and also for patients with a high risk of HBV infection. Vaccination can also be offered to any other individuals.

A3. Re-test of anti-HBs is recommended 1 month after the vaccine series for patients with high risk, such as healthcare workers (HCW), people who receives blood transfusions or on hemodialysis, and family members of infected people. If the titer is below 10 $\mathrm{IU} / \mathrm{L}$, vaccination must be repeated. If the titer is above $10 \mathrm{IU} / \mathrm{L}$, the patient is to be considered lifelong immunized - so neither re-vaccination nor anti-HBs follow up are necessary (except before immunosuppressive therapy).

A4. To exclude/confirm HDV infection, an anti-HD test is essential for all $\mathrm{HBsAg}$ positive patients. For anti-HD positive patients, anti-HD-lgM or HDV RNA test is necessary. A HDAg test can also be performed. HDAg test gives a positive result characteristically in case of acute HDV infection. The negative result of the HDAg test doesn't exclude chronic HDV infection (i.e., replication of HDV)!

A5. PCR for HBV DNA test is indicated if the HBsAg test is positive.

A6. Unless contraindicated, anti HBV therapy is recommended if HBV DNA is detectable and the activity of the disease and/or fibrosis is confirmed by biochemical, histological, or non-invasive methods. In addition, some other categories of HBV infected patients might need therapy.

A7. In case of acute severe or fulminant hepatitis B, early antiviral therapy (NA) is recommended according to the regulations for off-label administration.

A8. The first choice of anti HBV therapy can be IFN/PEG IFN or a NA.

A9. For both cost-effectiveness aspects and protection of the patients (side effects, drug resistance), follow up of viral kinetics during the therapy and also switching to another therapy when it is needed are emphasized.

A10. In case of replication of HDV (positive anti-HD IgM and/or HDV RNA and/or HDAg) chronic hepatitis D must be treated with IFN/PEG-IFN - independently of ALT/GPT values and the titer of HBV DNA. Concomitant NA therapy can be also indicated if HBV DNA is also detectable.

A11. For susceptible individuals, vaccination against hepatitis $A$ is recommended before or during $\mathrm{HBV} / \mathrm{HDV}$ therapy.

A12. Because of the increased risk of HCC, abdominal ultrasound is necessary for all patients with chronic HBV every year. For patients with cirrhosis, this ultrasound examination must be performed in every 6 months. 
Table 1. New terminology of phases of chronic HBV infection (3)

\begin{tabular}{|c|c|c|c|c|c|}
\hline New name & $\begin{array}{l}\text { HBeAg positive } \\
\text { chronic HBV } \\
\text { infection }\end{array}$ & $\begin{array}{c}\text { HBeAg positive } \\
\text { chronic } \\
\text { hepatitis B }\end{array}$ & $\begin{array}{l}\text { HBeAg negative } \\
\text { chronic HBV } \\
\text { infection }\end{array}$ & $\begin{array}{c}\text { HBeAg negative } \\
\text { chronic hepati- } \\
\text { tis B }\end{array}$ & $\begin{array}{c}\text { HBsAg negative } \\
\text { phase of chronic } \\
\text { HBV infection }\end{array}$ \\
\hline HBsAg titer & high & $\begin{array}{c}\text { high/ } \\
\text { intermediate }\end{array}$ & low & intermediate & negative \\
\hline Anti-HBs & negative & negative & negative & negative & $\begin{array}{l}\text { characteristically } \\
\text { negative but it can } \\
\text { also be positive }\end{array}$ \\
\hline $\mathrm{HBeAg}$ & positive & positive & negative & negative & negative \\
\hline HBV DNA load & $>10^{7} \mathrm{IU} / \mathrm{mL}$ & $10^{4}-10^{7} \mathrm{lU} / \mathrm{mL}$ & $<2 \times 10^{3} \mathrm{IU} / \mathrm{mL}$ & $>2 \times 10^{3} \mathrm{IU} / \mathrm{mL}$ & $\begin{array}{c}\text { characteristically } \\
\text { negative; } \\
\text { cccDNS in the } \\
\text { nucleus of liver } \\
\text { cells }\end{array}$ \\
\hline GPT/ALT & normal & elevated & normal & elevated & normal \\
\hline Liver damage & no/minimal & $\begin{array}{l}\text { intermediate/ } \\
\text { severe }\end{array}$ & no & $\begin{array}{l}\text { intermediate/ } \\
\text { severe }\end{array}$ & no \\
\hline Risk of HCC & low & increased & low & increased & $\begin{array}{l}\text { there is occurs in } \\
\text { case of cirrhosis }\end{array}$ \\
\hline Old name & $\begin{array}{l}\text { immune } \\
\text { tolerance }\end{array}$ & $\begin{array}{c}\text { immunoreactive } \\
\text { HBeAg positive } \\
\text { CHB }\end{array}$ & $\begin{array}{l}\text { inactive } \\
\text { carrier }\end{array}$ & $\begin{array}{c}\mathrm{HBeAg} \\
\text { negative } \\
\mathrm{CHB}\end{array}$ & $\begin{array}{l}\text { occult HBV } \\
\text { infection }\end{array}$ \\
\hline
\end{tabular}

Note: Possibility of an occult HBV infection (HBsAg negative phase of chronic HBV infection) should be considered in any HBsAg negative but anti-HBc positive patient. However, anti-HBc positivity itself does not prove HBV infection!

Abbreviations: HBsAg = HBV surface antigen; ALT/GPT = alanine transaminase; HBeAg = HBV e antigen; anti-HBe = antibody to the HBV e antigen; anti-HBs = antibody to the HBV surface antigen; $\mathrm{CHB}=$ chronic viral hepatitis B; HBV = hepatitis B virus; $\mathbf{H C C}=$ hepatocellular carcinoma; DNA = dezoxyribonucleic acid

2010) was accepted in 2010 and published in the official publication of Ministry of Health in 2011 (2). Members of the Committee were also involved in development of this financial protocol.

The aim of this guideline is to update previous recommendations from 2017. In this guideline, references can be found only for recommendations that are different from the once in the 2017 version or not included in it. This guideline doesn't substitute the directions of the regulations of drug labels published by the OGYÉl!

\section{Diagnosis}

\section{Confirmation of HBVIHDV infections and related liver disease}

Confirmation of HBV infection, HBV genotyping For all patients with liver disease and unknown HBV and/ or HCV status, HBsAg, anti-HBs, anti-HBC (and anti-HCV) serologies are recommended (Table 2). HBV vaccination is recommended if $\mathrm{HBsAg}$ and anti-HBs serologies are negative. $\mathrm{HBsAg}$ negativity and anti-HBc positivity must be documented in the medical record of the patient, because occult $\mathrm{HBV}$ infection is of great importance in blood donation and might be relevant in certain diseases and therapies.

Detection of $\mathrm{HBsAg}$ and/or $\mathrm{HBeAg}$, and/or $\mathrm{HBcAg}$, and/or HBV DNA confirms HBV infection. If persists for more than 6 months, confirms chronic HBV infection. Replication of HBV is to be confirmed by quantitative PCR for HBV DNA. It is recommended even if $\mathrm{HBsAg}$ and anti-HBs negative, but anti-HBC positive, and liver disease is suspected. Therapy-related PCR must be performed in laboratories working with ISO qualification and continuously take part in quality control, according to the following methodological and quality terms:

- real-time PCR with properly sensitive tests (qualification: CE-IVD),

- low detection limit of HBV DNA: lower limit of detection $\leq 20 \mathrm{IU} / \mathrm{mL}$,

- linear quantification range of HBV DNA: $20 \mathrm{IU} / \mathrm{mL}-10^{8}$ IU/mL,

- PCR results necessary to the treatment decisions must be ready in 5 working days after the arrival of the sample to the laboratory.

If possible, HBV genotyping is recommended. A and B genotypes of HBV respond better to IFN therapy than other genotypes.

\section{Confirmation of HDV infection}

All HBsAg positive patients should be screened for antiHD. If anti-HD is positive a positive anti HD-lgM and/or HDV RNA and/or HDAg confirms active HDV infection. The HDAg is characteristically positive in case of acute HDV infection. If the HDAg test is negative, it doesn't exclude chronic HDV infection, and replication of HDV! 
Table 2. Serological diagnosis of HBV infection; evaluation HBV status and recommendations

\begin{tabular}{|c|c|c|c|c|}
\hline \multicolumn{5}{|c|}{ Results of HBsAg, anti-HBs and anti-HBc serologies } \\
\hline Result & $\begin{array}{l}\text { HBsAg: neg } \\
\text { Anti-HBs: neg } \\
\text { Anti-HBc: neg }\end{array}$ & $\begin{array}{l}\text { HBsAg: neg } \\
\text { Anti-HBs: pos } \\
\text { Anti-HBc: neg }\end{array}$ & $\begin{array}{l}\text { HBsAg: neg } \\
\text { Anti-HBs: pos/neg } \\
\text { Anti-HBc: pos }\end{array}$ & $\begin{array}{l}\text { HBsAg: pos } \\
\text { Anti-HBs: neg } \\
\text { Anti-HBc: pos }\end{array}$ \\
\hline HBV status & $\begin{array}{l}\text { HBV receptive } \\
\text { (both actual and } \\
\text { past HBV infections } \\
\text { can be excluded) }\end{array}$ & $\begin{array}{l}\text { Vaccinated against } \\
\text { HBV }\end{array}$ & $\begin{array}{l}\text { Unclear HBV status; } \\
\text { may have recovered } \\
\text { from HBV infection, or } \\
\text { occult HBV infection }\end{array}$ & HBV infection \\
\hline Recommendation & $\begin{array}{l}\text { Vaccination } \\
\text { (except if a former } \\
\text { successful } \\
\text { vaccination is } \\
\text { confirmed }^{\star} \text { ) }\end{array}$ & $\begin{array}{l}\text { Anti-HBs >10 IU/L: } \\
\text { immunised, no } \\
\text { action required *; } \\
\text { Anti-HBs <10 IU/L : } \\
\text { Booster vaccination, } \\
\text { repeat anti-HBs titer } \\
\text { one month later }\end{array}$ & $\begin{array}{l}\text { In case of immuno- } \\
\text { suppression: } \\
\text { HBV DNA testing; } \\
\text { if HBV DNA positive: } \\
\text { occult HBV infection, } \\
\text { NA therapy }\end{array}$ & $\begin{array}{l}\text { HBeAg, anti-HBe, } \\
\text { anti-HBc IgM, } \\
\text { HBV DNA, anti-HD } \\
\text { testing, then } \\
\text { according to the } \\
\text { algorithm in Figure } 1 .\end{array}$ \\
\hline
\end{tabular}

* Confirmed >10 IU/I anti-HBs titre provides a lifelong immunization - repeat anti-HBs serology or booster vaccination is unnecessary even if the titer of anti-HBs decreases or becomes negative by time.

Abbreviations: HBV = hepatitis B virus; HBsAg = HBV surface antigen; anti-HBs = antibody to the HBV surface antigen; anti-HBc = antibody to the HBV core antigen; DNA = dezoxyribonucleic acid; NA = nucleot/side analogue; anti-HD = antibody to the HDV; $\mathrm{HBeAg}=\mathrm{HBV}$ e antigen; anti-HBe = antibody to the HBV e antigen; pos = positive; neg = negative

\section{Demonstration of HBV/HDV-related chronic liver disease (CLD)}

In HBV/HDV infected individuals, demonstration of CLD includes demonstration of chronic inflammation by elevated aminotransferases for $>6$ months (primarily GPT/ $\mathrm{ALT})$ and/or by histology ( $\mathrm{HAl}>1)$ and/or demonstration of fibrosis $(\mathrm{F} \geq 1)$ by liver biopsy, and/or by transient elastography (FiroScan, liver stiffness $\geq 6.0 \mathrm{kPa}$ ), and/or by any other elastography or validated non-invasive methods (e.g. FibroTest, ELF test, FIB-4-test). If the GPT/ALT is consistently elevated for $>6$ months and the titer of HBV DNA is above $2.000 \mathrm{IU} / \mathrm{mL}\left(2 \times 10^{3} \mathrm{IU} / \mathrm{mL}\right)$, liver biopsy as well as other fibrosis assessment methods can be omitted. Possible other causes of CLD must be considered and excluded.

\section{Aminotransferases}

Elevated GPT/ALT suggests active hepatitis but it may show permanently normal results in the immunotolerant phase of the infection, and it can also be intermittently normal in some $\mathrm{HBeAg}$ negative patients. Its long-term follow-up is essential for decision on therapy. Based on clinical studies, for patients with chronic hepatitis B the upper limit of normal GPT/ALT is $35 \mathrm{U} / \mathrm{L}$ for men and $25 \mathrm{U} / \mathrm{L}$ for women. Between these values and the (typically higher) normal values of a particular laboratory, results can be interpreted as 'borderline values. Elevated GPT/ALT three occasions lasting at least for 6 months confirms CLD and supports therapy, as well as one elevated GPT/ALT before the start of the therapy if HBV/HDV infection certainly/presumably persists for more than 6 months.

\section{Liver biopsy}

Hepatitis activity index (HAI) $>1$ with confirmed HBV infection for at least 6 months and/or fibrosis stage $\geq 1$ on histology confirm CHB. In HBV/HDV infected patients liver biopsy might be relevant and recommended for differential diagnosis and demonstration of other liver diseases.
Non-invasive fibrosis assessment. Liver stiffness (LS) $\geq 6,0$ $\mathrm{kPa}$ on transient elastography (FibroScan) and/or a fibrosis stage $\geq 1$ with any other validated non-invasive fibrosis assessment method (e.g. other elastographies, FibroTest, ELF test, FIB-4-test) also confirm $\operatorname{CLD}(3,4,6,7)$.

\section{Treatment initiation}

\section{Indications of HBVIHDV therapy}

\section{Goals of HBV therapy}

The primary aim of the therapy is the seroconversion of $\mathrm{HBsAg}$ to anti-HBs. If it is not achieved, the alternative aim is to reduce (or cease) the replication of HBV. Further, in case of $\mathrm{HBeAg}$ positivity, the aim is the seroconversion of $\mathrm{HBeAg}$ to anti-HBe. In this way, we can abolish/limit the inflammation in the liver, prevent or slow down progression, development of cirrhosis and liver failure, and the risk of $\operatorname{HCC}(8,9,10)$.

\section{No cirrhosis}

Treatment of non-cirrhotic HBV infected patients are recommended - independently of the HBeAg status -, if HBV-DNA is $\geq 2 \times 10^{3} \mathrm{IU} / \mathrm{mL}(2.000 \mathrm{IU} / \mathrm{mL})$ and ALT is elevated. If ALT is normal, liver biopsy and/or non-invasive fibrosis assessment is necessary and antiviral therapy is indicated if $\mathrm{HAl}>1$ and/or LS $\geq 6,0 \mathrm{kPa}$ on transient elastography (FibroScan), and/or fibrosis stage $\geq 1$ with any other validated non-invasive fibrosis assessment method (e.g. other elastographies, FibroTest, ELF test, FIB-4-test). If the titer of HBV DNA is $<2 \times 10^{3} \mathrm{IU} / \mathrm{mL}$, and no CLD can be demonstrated (GPT/ALT is normal, neither fibrosis nor active inflammation can be confirmed), therapy is not recommended (exceptions are mentioned in the section of special groups of patients) (5) - however these patients are to be followed for both viremia and liver disease activity. 


\section{Compensated cirrhosis}

Any patients with cirrhosis must be treated if HBV DNA is detected - independently of the viral titer and activity. The following results suggest cirrhosis: bridging fibrosis or definitive cirrhosis (Knodell F3-F4 or Ishak F4-F5-F6) by histology, and/ or by transient elastography (LS $>9.6 \mathrm{kPa}$ ) and/or by any other validated non-invasive fibrosis assessment method (e.g. any other elastography, FibroTest, ELF test, FIB-4-test). Child-Pugh score $<7$ confirms compensated liver disease.

\section{Decompensated cirrhosis}

In case of HBsAg positivity, patients with decompensated cirrhosis must be treated independently of the titer of HBV DNA (even if the titer is negative)! Child-Pugh score $\geq 7$ confirms decompensated liver disease.

HBV infection and chemotherapy, immunosuppressive or biological therapy

PCR for HBV DNA is recommended for patients with positive $\mathrm{HBsAg}$ and/or anti-HBc if they receive chemotherapy, immu- nosuppressive or biological therapy, or they've undergone organ/bone marrow transplantation. If the result is positive, the patient must be treated. Therapy might also be recommended for some patients with undetectable HBV DNA.

\section{CHD}

IFN/PEG-IFN therapy is recommended if anti-HDV IgM is positive - even if HBV DNA is not detectable! Patients with ChildPugh A cirrhosis must be treated with PEG-IFN in case of HDV-Ag or anti-HD-lgM positivity - independently of activity and of HBV DNA detectability. If HBV DNA is also detectable, concomitant NA therapy can be considered. PEG-IFN is not recommended in patients with decompensated cirrhosis.

\section{Additional assessments, measures prior to treatment}

- General clinical assessment, in particular, signs of hepatic decompensation (Child-Pugh parameters), signs of co-morbidities.

- HBeAg, anti-HBe serologies.

\section{Figure 1. Algorithm of diagnosis and treatment of chronic hepatitis B with or without hepatitis D}

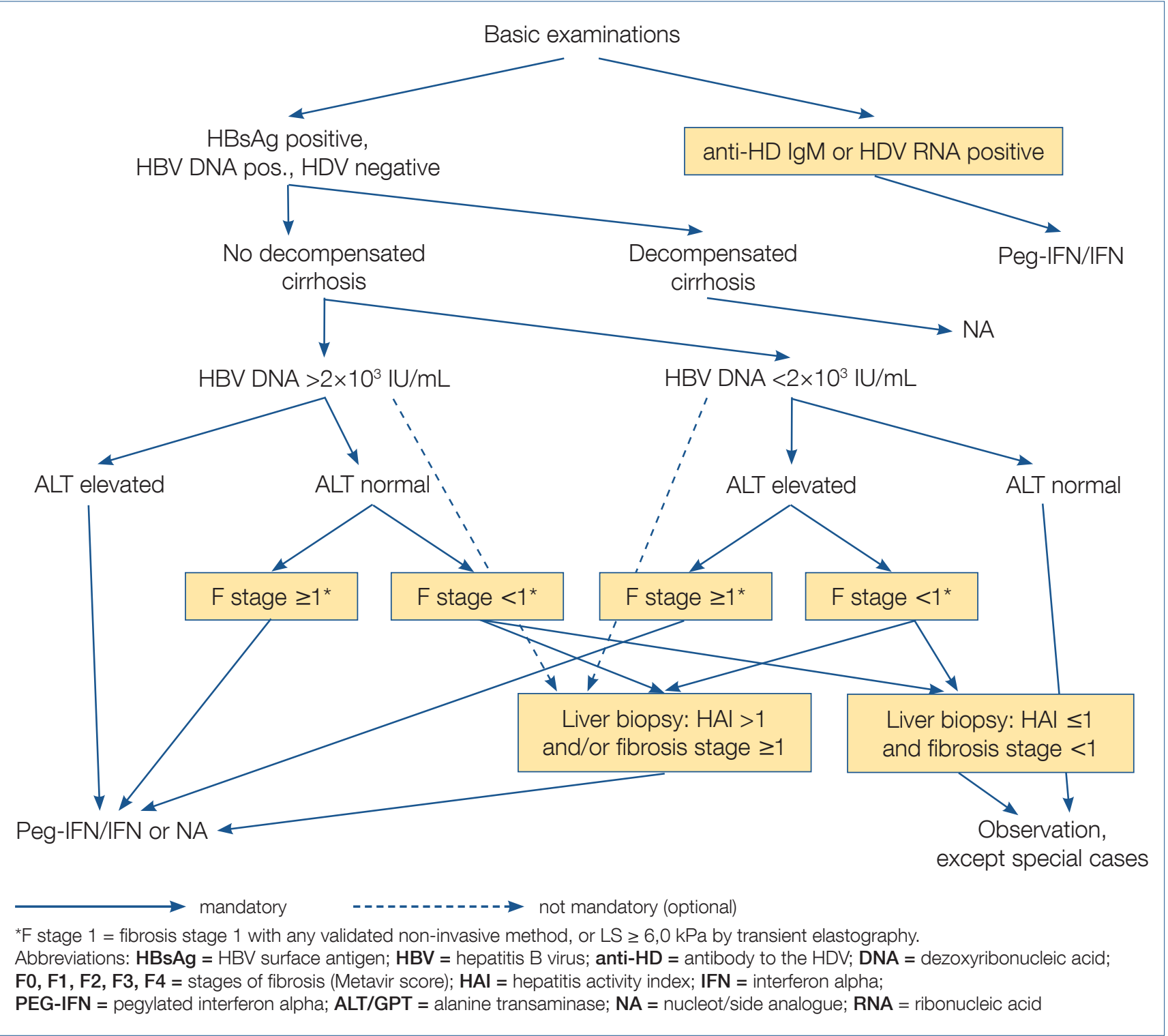


- HBsAg titer is useful in patients with chronic HBV infection, primarily for those, to be treated with INF/PEG-INF. Recommended, but not mandatory.

- HAV serology. Vaccination against hepatitis $A$ is recommended for susceptible patients, before or during the therapy.

- Anti-HCV, anti-HIV 1-2. If positive, appropriate diagnostics and therapy.

- Renal functions, TSH.

- Abdominal US (and further imaging if HCC is suspected). Examinations for co-existing liver diseases: autoimmune, alcoholic, metabolic liver diseases (including NAFLD, $\mathrm{NASH})$.

- Before starting therapy, the patient must be consulted by the attending/treating physician on HBV/HDV infections, on activity and stage of liver disease, on goals, modalities and conduct of therapy, on treatment options, on prognosis, on preventive measures, and on other relevant issues to obtain a signed informed consent of the patient. Figure 1 summarises algorithm of diagnosis and treatment of chronic hepatitis B with or without hepatitis D.

\section{Treatment options}

In most cases, the first choice of therapy can be either pegylated interferon-alpha (PEG-IFN) or a NA. For treatment decision, patient's preference is to be taken into account.

\section{Pegylated interferon alpha (PEG-IFN) therapy}

First line PEG-IFN therapy is recommended (if no contraindication):

- In HDV co-infected patients (anti-HD IgM, HDV RNA, or HDAg positive). Concomitant NA therapy for $\mathrm{CHB}$ might be considered.

Amongst other options, PEG-IFN therapy is preferred (but not mandatory):

- HBV therapy naive young patients ( $<40$ years),

- A or B genotypes of HBV,

- HBeAg negative patients, with:

- GPT/ALT >threefold of the upper limit of normal,

- HBV DNS $<2 \times 10^{8} \mathrm{IU} / \mathrm{mL}$,

$-\mathrm{HAI} \geq 2$,

Dose of PEG-IFN-alpha-2a: $1 \times 180 \mu \mathrm{g}$ per week, sc; $1 \times 135 \mu \mathrm{g}$ per week, sc if creatinine clearance is less than $30 \mathrm{~mL} / \mathrm{min}$.

Duration: 48 weeks; 72 weeks for anti-HD-IgM positive patients.

PEG-IFN is contraindicated in patients with decompensated cirrhosis.

\section{Measuring titer of HBV DNA and serologies during the IFN/ PEG-IFN therapy}

HBV DNA is recommended on week 24 of the therapy, at the end of therapy, on week 24 and week 48 after the therapy. In case of $\mathrm{HBeAg}$ positivity, $\mathrm{HBeAg}$ and/or antiHBe monitoring must be performed with the same schedule. In addition, monitoring of HBsAg titer is also recommended if available. After achieving seroconversion of $\mathrm{HBeAg}$ to anti-HBe, HBsAg test is recommended in every year if HBV DNA cannot be detected. When HBsAg becomes negative, anti-HBs serology must be performed.

\section{Evaluation of success of PEG-IFN therapy}

- On-treatment viral response: HBV DNA $<2 \times 10^{3} \mathrm{IU} / \mathrm{mL}$ at week 24 of the therapy

- Permanent viral response: HBV DNA $<2 \times 10^{3} \mathrm{IU} / \mathrm{mL}$ at the end of the therapy, and at week 24 and 48 after therapy.

- Non-adequate on-treatment viral response: not properly defined. Switching to NA therapy may be considered if the titer of HBV DNA $\geq 2 \times 10^{3} 1 \mathrm{U} / \mathrm{mL}$ and/or the HBV DNA load reduction is $<1 \log _{10}$ at week 24 of therapy.

- Breakthrough: re-occurrence of HBV viraemia or $1 \log _{10}$ elevation of the HBV DNS load any time during therapy. Switching to NA therapy is recommended.

- Multiple studies have confirmed that reduction of the titre of HBsAg during the PEG-IFN is a positive predictor of permanent viral response and also of HBsAg seroconversion.

\section{Additional monitoring during IFN/PEG-IFN therapy}

- Laboratory monitoring is necessary during the IFN/PEGIFN therapy: full blood count, GPT/ALT, GOT/AST, serum bilirubin (in every 4 weeks), serum creatinine, blood sugar, TSH, and uric acid (in every 12 weeks).

\section{Additional monitoring after IFN/PEG-IFN therapy}

- During (and after) the therapy, abdominal US must be performed in annually; every 6 months for patients with cirrhosis.

- After the end of the therapy, liver function and full blood count must be monitored at least every 6 months.

- For HBsAg positive patients and/or if HBV DNA is detectable, HBV DNA must be followed annually after the end of therapy. If HBV DNA is undetectable, monitoring of $\mathrm{HBsAg}$ is also recommended. If $\mathrm{HBsAg}$ becomes negative, anti-HBs serology must be performed.

\section{Nucleotide/nucleoside analogue (NA) therapies}

If not contraindicated, NA therapy can be chosen for the following patients:

- Amongst other options, a NA can be the first choice of therapy in any anti-HD IgM and HDV RNA negative HBV infected patients, regardless of HBeAg status.

- If no-adequate on-treatment viral response to IFN therapy.

- If there is breakthrough during IFN therapy.

- If there is no response after the 48-week IFN therapy.

- If after response to the IFN therapy, there is a relapse.

- As a second choice of therapy in case of drug resistance (in such a case, it can be administered even in combination).

- For HBsAg and/or HBV DNA positive patients before, during and after biological-, immunosuppressive-, or chemotherapy.

- HBsAg and/or HBV DNA positive patients who have undergone organ transplantation.

- Prophylaxis for patients with HBV who undergone organ or bone marrow transplantation

- In any stage of cirrhosis caused by HBV. 
Table 3. Recommendations for selection of entecavir (ETC) or tenofovir alafenamide fumarate (TAF) therapy instead of tenofovir dipivoxil fumarate (TDF)*

Age over 60 years
Renal impairment or a high risk of renal
impairment
- eGFR <60 $\mathrm{mL} / \mathrm{min}$
- Albuminuria $>30 \mathrm{mg} /$ day, proteinuria
- Hypophosphataemia
- Active glomerulonephritis
- Hemo-/peritoneal dialysis
- Status after any organ transplantation
- Not (well) controlled high blood pressure
- Not (well) controlled diabetes mellitus
- Taking other potentially nephrotoxic drugs

Any bone disease or a high risk of bone disease

- Permanent therapy of steroids

- Permanent therapy of any drugs which decrease the bone density

- Pathologic fracture of bones in the patient's history

*ETC, if the patient has not received LAM or other NA yet. Per label dose modification is necessary if eGFR $<50 \mathrm{~mL} / \mathrm{min}$.

${ }^{*} \mathrm{TAF}$, if the patient has already received LAM or other NA.

Abbreviations: eGFR = estimated glomerular filtration rate;

ETC = entecavir; TAF = tenofovir alafenamide fumarate;

TDF $=$ tenofovir disoproxil fumarate

- In case of any contraindications of IFN.

- Even for anti-HDV IgM positive patients if the titer of HBV DNA is consistently or intermittently $>2000 \mathrm{IU} / \mathrm{mL}$ and IFN therapy is contraindicated or it is not effective.

- Recommendations for unsuccessful NA therapy or NA resistance are listed in Table 3.

\section{Duration of NA therapy}

- NA therapy can be terminated if there is no detectable HBV DNA and HBsAg becomes negative (independently of anti-HBs!).

- In case of HBsAg positivity, terminating the NA therapy can be considered if ALT/GPT <ULN, there is no cirrhosis, progression of fibrosis cannot be detected, regular follow up of the patient after the cessation of therapy can be guaranteed, and

- for HBeAg positive patients: HBeAg to anti-HBe seroconversion is achieved and HBV DNA cannot be detected for 12 months of maintenance therapy,

- for $\mathrm{HBeAg}$ negative patients: if fibrosis stage is $<3$, and HBV DNA is not detectable for at least 3 years, and there is no (and there wasn't) any extrahepatic manifestations of HBV.

HBV DNA and serology follow up during NA therapy

- HBV DNA test is recommended in every 6 months (every three months in cirrhotics) after the initiation of NA therapy, and whenever increase of GPT/ALT or other clinical/ laboratory parameter suggests potentially inadequate viral response or breakthrough during the therapy.
- After the first year of ETC, TDF or TAF therapy, annual HBV DNA testing is sufficient, if last HBV DNA is not detectable and GPT/ALT is normal.

- For HBe positive patients on NA therapy, HBeAg and/or anti-HBe testing is recommended in every six months.

- For HBeAg negative patients on NA therapy, or after $\mathrm{HBeAg}$ to anti-HBe seroconversion, annual HBsAg testing is recommended if HBV DNA is undetectable. After HBsAg becomes negative, an anti-HBs serology must be performed.

\section{Additional follow up during NA therapy}

- During NA therapy, liver functions and blood counts to be followed in every 3 months. Significant increase in GPT/ALT suggests HBV breakthrough due to a NA resistance-associated substitution/mutation (RAS). RAS testing is recommended - if available. If RAS is confirmed, or RAS testing is not available, switching to another medication is recommended.

- During TDF/TAF therapy renal functions to be followed every month in the first three months of therapy, thereafter - if stable - at least in every three months.

- During (and after) HBV therapy, annual abdominal US is necessary to screen for HCC. Patients with cirrhosis are to be examined in every 6 months.

\section{Evaluation of on-treatment and post-treatment effi- cacy of NA therapy}

- Complete viral response: HBV DNA is not detectable.

- Partial viral response: There is a reduction of HBV DNA titer at month 6 of therapy or later on, to $>2 \times 10^{3} \mathrm{lU} /$ $\mathrm{mL}$, but HBV DNA is still detectable. Except the patient receives ETC, TDF or TAF, switching to another NA or a combined NA therapy is recommended, or IFN therapy can also be considered. In case of switch to INF therapy, ongoing ETC, TDF or TAF therapy to be continued.

- Breakthrough: Re-occurrence of viraemia or increase of HBV DNA titer by $1 \log _{10}$. RAS testing is recommended if available. If RAS is confirmed, or RAS testing is not available, switching to another medication is recommended. - Permanent viral response: titer of HBV DNA $<2.000$ $\mathrm{IU} / \mathrm{mL}$ during and at least 1 year after the end of NA therapy.

Recommendations at the end and after NA therapy

- At the end of therapy, and thereafter at least every 6 months (more frequently if unstable): full blood counts, liver functions.

- At the end of therapy, and 6 and 12 months thereafter: HBV DNA; for $\mathrm{HBeAg}$ positive patients, $\mathrm{HBeAg}$ and anti-HBe. For $\mathrm{HBeAg}$ negative patients, $\mathrm{HBsAg}$ and anti-HBs.

- After 48 weeks of post-treatment follow-up: HBV DNA annually in the case of HBsAg positivity and/or if HBV DNA is detectable. In case of undetectable HBV DNA, $\mathrm{HBsAg}$ testing is recommended. If HBsAg becomes negative, anti-HBs testing is recommended. 
- After discontinuation of HBV therapy: annual abdominal US to screen for HCC; every 6 months in patients with cirrhosis are to be examined in.

\section{Entecavir (ETC)}

- ETC is one of the most effective types of NAs and there is only a very little risk of drug resistance. According to the European guideline, it is one of the first drugs of choice of NA therapy. Its effectiveness and safety are confirmed even for patients with decompensated cirrhosis of the liver.

- ETC is the first choice of NA therapy for patients with renal impairment - dose to be adjusted according to the label.

- Because of the risk of developing another resistance, in case of LAM resistance, ETC is recommended only if TDF/ TAF are not available or contraindicated.

- In case of resistance to ETC or if there is detectable HBV DNA at week 96 of ETC therapy, switching to TDF or TAF is recommended.

- Dose of ETC: For NA näive patients: $1 \times 0.5$ mg daily, per os.; $1 \times 1,0 \mathrm{mg}$ daily, per os in case of resistance to LAM (not recommended if TDF/TAF can be prescribed) and in patients with decompensated cirrhosis. For patients with decompensated cirrhosis, TDF or TAF might be more cost-effective than ETC, thus TDF/TAF is recommended (if there is no contraindication). Reduced dose might be appropriate for patients with renal impairment, according to the label.

\section{Tenofovir disoproxil fumarate (TDF)}

- TDF is one of the most effective NAs, resistance is not known so far. Amongst other options, the European $\mathrm{HBV}$ guideline recommends it as one of the first drugs of choice of NA therapy.

- TDF is recommended in case of drug resistance to LAM, ADV, or ETC.

- However, ETC or TAF is recommended instead of TDF for patients with bone or kidney diseases or if there is a high risk of these diseases (Table 4).

- Dose of TDF: $1 \times 245 \mathrm{mg}$ daily, per os.

- During the therapy, kidney function must be followed regularly (every month during the first three months, then at least in every 3 months if stable).

\section{Tenofovir alafenamide fumarate (TAF)}

- TAF is an alternative of, and as effective as TDF. According to the clinical studies, TAF affects kidney function and bone density in a lower extent than TDF.

- ETC or TAF is recommended instead of TDF for patients with bone or kidney diseases or if there is a high risk of these diseases (Table 4).

- In Child-Pugh B and C stages of cirrhosis, we have no data about the effectiveness and safety of TAF, thus it is not recommended. In every other case, indications and duration of the therapy are the same as of TDF. After it was accepted, - amongst other options - it could be recommended as a first-choice therapy (depending on the price).

- Dose of TAF: $1 \times 25 \mathrm{mg}$ daily, per os.

\section{Table 4. Recommendations for second and third line therapies if NA resistance is confirmed or suspected}

\begin{tabular}{|c|c|c|}
\hline Initial NA(s) & Second line NA & Third line NA(s \\
\hline Lamivudine & tenofovir ${ }^{\star}$ & \\
\hline Adefovir & entecavir & tenofovir* \\
\hline Entecavir & tenofovir ${ }^{\star}$ & \\
\hline Multiple NAs & tenofovir* & $\begin{array}{l}\text { tenofovir* } \\
+ \text { entecavir }\end{array}$ \\
\hline
\end{tabular}

* tenofovir disoproxil fumarate or tenofovir alafenamide fumarate (see Table 3.)

Abbreviation: NA = nucleot/side analogue

\section{Adefovir dipivoxil (ADV)}

- Currently not available in Hungary.

- ADF is less effective than TDF, and the risk of resistance is higher. For this reason, ADF is not recommended as first line therapy, if other options are available (particularly not as monotherapy).

- Upon TDF and TAF are contraindicated or not available, ADV+LAM combination therapy is recommended in case of LAM resistance. However, switching to TDF or TAF is more effective in case of LAM resistant HBV.

- In case of resistance to ADV, switching to ETC or TDF or TAF is recommended. If the viral titer is $\geq 10^{8} \mathrm{IU} / \mathrm{mL}$, ETC is recommended.

- Dose of ADV: 1×10 mg daily, per os. For patients with renal impairment, the dose to be reduced according to the label.

\section{Lamivudine (LAM)}

- The risk of drug resistance during LAM therapy is high, especially if it is administered as monotherapy. Consequently, initiating new LAM therapy for CHB is indicated only if other NAs contraindicated or not available.

- Ongoing LAM therapy can be continued as long as there is no advanced liver disease $(\mathrm{F}<3)$, and HBV DNA is $<20$ $\mathrm{IU} / \mathrm{mL}$.

- Preventive LAM therapy can also be considered during and after biological-, immunosuppressive-, or chemotherapy for HBV DNA and HBsAg negative, anti-HBC positive patients with no advanced liver disease $(F<3)$ if expected duration on LAM therapy is not longer than 1 year.

- For patients with cirrhosis, LAM monotherapy is contraindicated.

- HBV DNA titer $\geq 20 \mathrm{IU} / \mathrm{mL}$ during LAM therapy suggests LAM resistance. Switching to TDF or TAF, or - if TDF or TAF is contraindicated or not available - combination of LAM with $A D V$ is recommended. ETC therapy carries a higher risk of resistance in case of LAM resistance.

- Dose of LAM: 1×100 mg daily, per os. For patients with renal impairment, dose reduction or switching to ETC (monotherapy) is recommended, depending on the eGFR. 
NA plus PEG-IFN add-on therapy (11)

- Add-on NA+PEG-IFN therapy can be chosen for HBeAg positive or $\mathrm{HBeAg}$ negative patients with $\mathrm{CHB}$ if $\mathrm{HBeAg}$ or $\mathrm{HBsAg}$ seroconversion was not achieved after at least one-year of NA monotherapy, respectively.

- Dose: same as for monotherpies.

- Recommended duration: 48 weeks. Thereafter, continuation of NA therapy is recommended as long as for NA monotherapy.

- Lab tests during and after the combined therapy: same as for PEG-IFN and NA monotherapies.

Special patient groups

HBeAg positive patients above 30 years

Antiviral therapy is recommended for $\mathrm{HBeAg}$ positive patients if they are older than 30 years and the titer of HBV DNA is high $\left(>2 \times 10^{3} \mathrm{IU} / \mathrm{mL}\right)$ even if the value of the GPT/ ALT is normal. For this group, antiviral therapy (IFN/PEGIFN, ETC, TDF or TAF) is recommended independently of the degree of activity and fibrosis.

\section{Patients with increased complication risk based on family history}

Regardless of HBeAg status, patients with chronic HBV infection and family history of HCC or of cirrhosis and/or extrahepatic manifestation, antiviral therapy should be considered (IFN/PEG-IFN, ETC, TDF or TAF).

\section{Patients with compensated cirrhosis}

For patients with compensated cirrhosis, std-IFN, PEG-IFN alpha-2a, ETC, TDF or TAF are recommended because of the low risk of drug resistance. NA therapy must be continued lifelong. Discontinuation of NA therapy may be considered one year after $\mathrm{HBeAg}$ to anti-HBe, or - with more confidence - after HBsAg to anti-HBs seroconversion, if HBV DNA is undetectable.

\section{Patients with decompensated cirrhosis}

HBsAg positive patients with decompensated cirrhosis require lifelong antiviral therapy (independently of detectability or titer of HBV DNA). ETC must be administered in a high dose (1.0 $\mathrm{mg}$ per day) while TDF must be administered in a normal dose $(1 \times 1.25 \mathrm{mg}$ per day). If there is no contraindication, TDF is the first choice NA therapy or switching to TDF is indicated (based on costeffectiveness). TAF might be a better option, especialyly in cases with impaired kidney function, however the safety and efficacy of TAF has not been confirmed in these patients so far, thus it is not recommended. Discontinuation of NA therapy may be considered one year after $\mathrm{HBeAg}$ to anti-HBe, or - with more confidence after HBsAg to anti-HBs seroconversion, if HBV DNA is undetectable.

\section{HBV infected liver transplant recipients}

Before the transplantation, each $\mathrm{HBsAg}$ positive patient is to receive NA therapy (ETC or TDF) in order to reach the lowest possible titer or undetectability of HBV DNA by the time of transplantation.

\section{Table 5. Recommended prophylaxis after the transplantation}

\section{Recipient}

Prophylaxis

HBsAg pos

$\mathrm{HBIG}$ + entecavir

Anti-HBs pos and anti-HBc pos

not necessary

Anti-HBs neg and anti-HBc pos

entecavir

Anti-HBs pos and anti-HBc neg

(successfully vaccinated)

entecavir

Anti-HBs neg and anti-HBc neg (näiv) entecavir

$\mathrm{HBIG}=\mathrm{HBV}$ immunoglobulin; HBsAg = HBV surface antigen; anti-HBc = antibody to the HBV core antigen;

anti-HBs = antibody to the HBV surface antigen

After the transplantation, NA therapy seems to be effective and safe, and recommended lifelong to prevent recurrence of HBV. HBsAg positive patients at the time of the transplantation are also to receive HBIG therapy.

\section{Patients after liver transplantation from HBsAg negative/anti-HBc positive donor}

Recommended prophylaxis after the transplantation is listed in Table 5.

\section{Solid organ graft recipients transplanted from a HBsAg negative/anti-HBc positive donor}

Transplantation of a HBsAg negative/anti-HBc positive donor organ to a HBsAg negative/anti-HBc positive or negative recipient is not contraindicated if the anti-HBs titer $\geq 10$ $\mathrm{IU} / \mathrm{mL}$ at both the donor and the recipient. The recipient must be on ETC or TDF therapy for at least 6 months after transplantation. ETC must be preferred in case of renal impairment or if there is a high risk of it. Regular HBV serologies ( 3 and 6 months after transplantation, every 6 months thereafter) and HBV DNA PCRs ( 6 months after transplantation, thereafter annually) are recommended. If there is any suspicion of viral reactivation, unscheduled HBV DNA testing is recommended.

\section{Patients with solid organ transplantation from HBsAg positive donor}

Transplantation of a solid organ from a HBsAg positive donor is generally not recommended, but can be acceptable in desperate circumstances. In particular, liver transplantation can only be acceptable if there is no relevant liver damage in the donor liver by histology.

After the transplantation of any organs, NA prophylaxis is mandatory. Administration of HBIG is also necessitated if the anti-HBs titer in the recipient is $<100 \mathrm{mIU} / \mathrm{L}$. Follow up of HBV DNA, HBsAg and anti-HBs is recommended in every three months in the first year; thereafter in every 3-6 month.

\section{Patients with HBV and HIV co-infections}

Indication and conduct of HBV therapy is the same as for HIV negative patients. In most cases, simultaneous de novo therapy of HIV and HBV is recommended (TDF, emtricitabine, and a third anti-HIV medication). 
If HBV therapy is initiated prior to HIV therapy, ADV or telbivudine should be chosen because they have no confirmed effect on HIV virus. LAM, ETC or TDF monotherapy for HBV is contraindicated without concomitant therapy for HIV in co-infected patients, because as monotherapy they may induce HIV viral resistance due to their anti-HIV activity.

\section{Patients with HBV and HCV co-infections}

The titer of HBV DNA is usually low or undetectable in HCV co-infected patients. HCV co-infected patients can be treated for HBV with NAs, according to the guidelines for HBV mono-infection. Furthermore, reactivation of HBV may occur during or after the DAA therapy of HCV; if it occurs, NA therapy is to be initiated.

$\mathrm{HCV}$ can also be treated in HBV co-infected patients according to the guidelines for HCV mono-infection. Efficacy is the same as for HCV mono-infected patients. HBsAg, anti-HBs and anti-HBc serologies are necessary before DAA therapy. HBsAg positive patients should receive NA therapy at the same time, because of the HBV infection. This NA therapy must be continued at least 24 weeks after the end of the therapy of HCV.

$\mathrm{HBsAg}$ negative but anti-HBc positive patients require strict follow up during HCV therapy: ALT/GPT in every month during the therapy and 1,3, and 6 months thereafter. If the HCV RNA is negative but ALT/GPT is not normalized or rises during or after HCV therapy, HBsAg and HBV DNA testing are recommended. Co-administration of NA therapy is recommended if HBV flare is confirmed or suspected!

Drug-drug interactions of may occur during simultaneous therapy of HBV and HCV (Table 6).

\section{Patients with chronic hepatitis D co-infection}

IFN/PEG-IFN is the only evidence-based therapy for HDV infection. Duration of the therapy is one and a half year; in case of a relapse, the therapy should be repeated.

NAs don't have any effect on the replication of the HDV but co-administration of a NA can be recommended if HBV
DNA is $>2 \times 10^{3} \mathrm{IU} / \mathrm{mL}$ consistently or intermittently or other indications of HBV treatment mandate.

After a successful PEG-IFN therapy of chronic hepatitis D (IgM anti-HD and/or HDV RNA negative), therapy must be continued as for chronic HBV infection.

\section{Patients with fulminant or progressing severe acute hepatitis B}

NA therapy may be beneficial. Some publications report benefit of LAM therapy, but this is not properly proved in randomized clinical trials yet. ETC, TDF, TAF have excellent anti-HBV potential and low risk of viral resistance should be preferred. Optimal duration of the therapy is unknown, but continuation as long as in case of $\mathrm{CHB}$ is reasonable and recommended. Differentiation of real severe acute hepatitis $B$ and from a relapse of $\mathrm{CHB}$ can be difficult. Liver biopsy might be necessary. In both cases, NA is the therapy.

\section{HBV infected children}

The effectiveness and safety of IFN, LAM, ADV, and entecavir are confirmed for children above 2 years of age.

\section{HBV infected healthcare workers (HCWs)}

For HBsAg and HBV DNA positive HCWs, IFN/PEG-IFN, ETC, TDF or TAF is recommended.

\section{HBV infected women who plan pregnancy}

\section{No advanced fibrosis ( $F \leq 2)$}

Anti-HBV therapy with a 48 week IFN/PEG-IFN prior to pregnancy may be considered with a 6 months post-treatment interval before pregnancy. Alternatively, therapy of HBV should be postponed after delivery. Proper contraception is mandatory during IFN/PEG-IFN therapy.

\section{Compensated, but advanced liver disease (F3 or F4 fibrosis)} A 48 week IFN/PEG-IFN therapy with a 6 months posttreatment interval before pregnancy is recommended for HBV infected women with advanced fibrosis

\section{Table 6. Potential interactions of recommended NAs and DAAs during concomitant treatment of} HBV and HCV

\begin{tabular}{|c|c|}
\hline 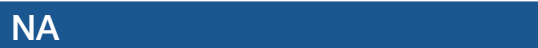 & Tenofovir* \\
\hline \multicolumn{2}{|c|}{ HCV therapy (available currently in Hungary) } \\
\hline \multicolumn{2}{|c|}{ Elbasvir+gazoprevir } \\
\hline \multicolumn{2}{|l|}{ OBV/PTV/r+DSV } \\
\hline \multicolumn{2}{|l|}{ Glecaprevir+pibrentasvir } \\
\hline Ledipasvir+sofosbuvir & \multirow{3}{*}{$\begin{array}{l}\text { Level of tenofovir* can be elevated } \\
\text { in the blood. Side effects of tenofo- } \\
\text { vir* must be strictly monitored. }\end{array}$} \\
\hline Velpatasvir+sofosbuvir & \\
\hline Sofosbuvir+velpatasvir+voxilaprevir & \\
\hline \multicolumn{2}{|c|}{$\begin{array}{l}\text { * tenofovir disoproxil fumarate or tenofovir alafenamide fumarate } \\
\text { Green: Clinically significant interactions of drugs are not expected. } \\
\text { Orange: Clinically significant interactions of drugs may occur- but co-administration with close monitoring for interactions is possible if no } \\
\text { better option is available. } \\
\text { Red: These drugs are not to be co-administered because the high risk of a clinically significant interactions (does not occur in these cases). } \\
\text { Source: http://www.hep-druginteractions.org/checker }\end{array}$} \\
\hline \multicolumn{2}{|c|}{$\begin{array}{l}\text { Abbreviations: HBV = hepatitis B virus; HCV = hepatitis C virus; DAA = direct acting antiviral agents; NA = nucleot/side analogue; } \\
\text { OBV/PTV/r+DSV = ombitasvir/paritaprevir/ritonavir/dasabuvir }\end{array}$} \\
\hline
\end{tabular}


but compensated liver disease. Proper contraception is mandatory during IFN/PEG-IFN therapy. If IFN/PEGIFN therapy is ineffective or contraindicated, tenofovir therapy to be initiated and to be continued during and after the pregnancy (as long as for CHB treatment), after detailed counseling with the patient (and family) on potential risks and benefits of this therapy during pregnancy (15).

\section{Decompensated liver disease}

Childbearing potential is low, pregnancy carries high maternal and fetal risks, INF/PEG-IFN is contraindicated, NAs are either contraindicated or not recommended in first two trimesters of pregnancy. For this reasons, pregnancy is not recommended for HBV infected women with decompensated liver disease. TDF (or ETC) therapy is to be initiated, and liver transplantation is to be considered.

HBV infected pregnant women $(12,13)$

According to the FDA, LAM, ADV, and ETC classified into pregnancy risk category $C$, telbivudine and TDF into category B. IFN/PEG-IFN is contraindicated.

Recommendations for initiating new HBV therapy are identical as for HBV infected women who plan pregnancy. Continuation or discontinuation of an ongoing HBV therapy is to be re-considered and to be counseled with a woman who becomes unexpectedly pregnant. TDF therapy may be continued, while IFN/PEG-IFN, LAM, ADV, or ETC therapy should be switched to TDF (mandatory in fibrosis stage F3 or F4).

To prevent perinatal transmission, in all pregnant women with HBV DNA $>2 \times 10^{5} \mathrm{IU} / \mathrm{ml}$ or HBsAg $>1 \times 10^{4} \mathrm{IU} / \mathrm{ml}$, TDF prophylaxis should start at week 24-28 of gestation and continue for up to 12 weeks after delivery.
HBsAg positive mothers are to be strictly followed after delivery, because of the risk of acute flare of HBV hepatitis (even if the HBV infection did not require treatment previously).

\section{Newborns of HBV infected mother}

Passive and active immunization of newborn of a HBV infected mother (HBsAg and/or HBV DNA positive) is mandatory in the perinatal period (within 12 hours after birth). However, even with passive and active immunization, the risk of the vertical transmission remains still high (>10\%) if viral load of mother is high in the prenatal period. To decreases the viral load and make active plus passive immunization more effective, from week 24-28 of gestation TDF therapy is recommended for pregnant women with $\mathrm{HBV}$ DNA $>2 \times 10^{5} \mathrm{IU} / \mathrm{ml}$ or $\mathrm{HBsAg}>1 \times 10^{4} \mathrm{IU} / \mathrm{ml}$ (13).

Breast feeding is NOT contraindicated, neither for $\mathrm{HBsAg}$ positive untreated women nor during TDF therapy! Concentration of TDF in breast milk is relatively low.

\section{Patients who receive chemotherapy, immunosupp- ressive or biological therapy, bone marrow or stem cell transplantation (together: interventions)}

For patients with either inactive HBV infection (HBsAg positive, no liver damage, no sign of hepatitis) or occult HBV infection (HBsAg negative, anti-HBc positive, no liver damage, no sign of hepatitis) receiving any of such therapies carries a severe risk of reactivation of HBV infection, including fulminant hepatitis. Therefore, HBsAg, anti-HBs and anti-HBc are to be screened prior to any of these interventions. If any of the results is positive, hepatology consultation is recommended. Furthermore, non-immune (seronegative) patients should be actively immunized against hepatitis $B$.

\section{Table 7. Risks of reactivation of HBV in case of various immunosuppressive and biological} therapies

\begin{tabular}{|c|c|c|c|c|c|c|}
\hline Risk of HBV reactivation & \multicolumn{2}{|c|}{ High $(>10 \%)$} & \multicolumn{2}{|c|}{ Intermediate (1-10\%) } & \multicolumn{2}{|c|}{ Low $(<1 \%)$} \\
\hline Anti-HBc positive and & $\begin{array}{l}\text { HBsAg } \\
\text { pos. }\end{array}$ & $\begin{array}{l}\text { HBsAg } \\
\text { neg. }\end{array}$ & $\begin{array}{l}\text { HBsAg } \\
\text { pos. }\end{array}$ & $\begin{array}{l}\text { HBsAg } \\
\text { neg. }\end{array}$ & $\begin{array}{l}\text { HBsAg } \\
\text { pos. }\end{array}$ & $\begin{array}{l}\text { HBsAg } \\
\text { neg. }\end{array}$ \\
\hline Anti-CD20 & X & X & & & & \\
\hline Anthracyclin derivates & $X$ & & & $X$ & & \\
\hline $\begin{array}{l}\text { High or intermediate doses of oral } \\
\text { steroid for } \geq 4 \text { weeks }\end{array}$ & $X$ & & & $X$ & & \\
\hline Anti-TNF- $\alpha$ & & & X & X & & \\
\hline Other inhibitors of cytokines or integrins & & & X & $x$ & & \\
\hline Tyrosine kinase inhibitors & & & X & X & & \\
\hline Small dose of oral steroid for $\geq 4$ weeks & & & X & & & X \\
\hline Azathioprine, methotrexate & & & & & X & X \\
\hline Intra-articular teroids & & & & & X & X \\
\hline Oral steroid for $<1$ week & & & & & $x$ & X \\
\hline
\end{tabular}

High dose of steroid: $>20 \mathrm{mg} /$ day prednisone or equivalent.

Intermediate dose of steroid: $>10 \mathrm{mg} /$ day to $\leq 20 \mathrm{mg} /$ day prednisone or equivalent.

Small dose of steroid: $\leq 10 \mathrm{mg} /$ day prednisone or equivalent.

Abbreviations: HBsAg = HBV surface antigen; anti-HBc = antibody to the HBV core antigen; HBV = hepatitis B virus;

Anti-CD20 = monoclonal antibody to CD20; anti-TNF- $\alpha=$ antibody to tumor necrosis factor alpha 
Regardless of HBsAg status, PCR for HBV DNA is recommended for all anti-HBc positive patients. (14) For HBsAg and/or HBV DNA positive patients, NA therapy (ETC, TDF or TAF) is to be initiated prior to (preferably) or during such interventions, and to be continued for at least one year after the completion of intervention. In case of rituximab mono- or combination therapy, NA prophylaxis should continue for at least one and a half years after stopping the intervention, and close monitoring should continue for an additional year threreafter. Anti-HBc positive but HBsAg and HBV DNA negative patients are to be strictly followed during and after such interventions: monthly GPT/ALT, and anti-HBs titer every 3 months (if previous anti-HBs titer is above $100 \mathrm{IU} / \mathrm{L}$ ) or HBV DNA level every 3 months if anti-HBs is below $100 \mathrm{IU} / \mathrm{L}$.

If regular follow up of HBV DNA is not available or the anti-HBs titer is below $100 \mathrm{IU} / \mathrm{L}$, NA prophylaxis is recommended for all anti-HBc positive, HBsAg negative patients who receive rituximab and/or combination chemotherapy because of a malignant hematologic disease $(15,16,17)$.

NA prophylaxis is also recommended for anti-HBc positive, $\mathrm{HBsAg}$ and HBV DNA negative patients who receive bone marrow or stem cell transplantation (independently of the titer of anti-HBs) (18).

ETC, TDF or TAF is recommended for prophylaxis; LAM can only be used if its duration is not longer than one year. Duration of prophylactic NA therapy is be consulted between the haematologist(s) and hepatologist(s).

In case of HBV reactivation, NA therapy is to be initiated, and to be continued for at least one and a half years after completion of intervention.

Table 7 and Table 8 show the risks and recommendations for patients who receive immunosuppressive or biological therapy $(19,20,21)$.

\section{Patients on hemodialysis or after kidney}

transplantation

Either a NA or IFN/PEG-IFN therapy can be chosen for patients with chronic kidney disease. ETC is the optimal therapy for kidney transplanted patients - IFN/PEG-IFN is contraindicated.

\section{Patients with extrahepatic manifestations}

IFN, PEG-IFN or a NA can be considered for HBsAg positive and/or HBV DNA positive patients with HBV-related extrahepatic manifestations. However, IFN/PEG-IFN may be even unfavorable, harmful, or contraindicated in certain immune-mediated extrahepatic manifestations.

In special cases, NA therapy combined with plasmapheresis may increase effectiveness.

\section{Conclusions}

HBV infection can cause severe (even fatal) acute hepatitis, and may lead to end stage liver disease as well as to HCC (even in patients with otherwise not relevant liver disease). These outcomes and related financial burden can be greatly reduced with immunization and screening programs, and with effective therapies.

The incidence, and - in a smaller extent - the prevalence of HBV have been recently reduced in countries with immunization programs, including Hungary. Unfortunately, prevalence is still significant in non-immunized individuals (born before 1986 in Hungary). Extension of immunization program to yet not included populations - especially for those at risk - is at upmost importance, and may prove cost-effective from health-economy and societal aspects. As of therapy, it is considered effective if replication of HBV is blocked completely, or reduced to a minimal level. If it is

\section{Table 8. Recommendations for anti-HBc positive patients who receive biological or immunosuppressive therapy}

\begin{tabular}{|c|c|c|c|c|}
\hline \multirow[b]{2}{*}{ Treatment } & \multirow{2}{*}{$\begin{array}{c}\text { HBsAg pos. } \\
\text { HBV DNA pos. } \\
\text { or neg. }\end{array}$} & \multirow{2}{*}{$\begin{array}{l}\text { HBsAg neg. } \\
\text { HBV DNA } \\
\text { pos. }\end{array}$} & \multicolumn{2}{|c|}{ HBsAg and HBV DNA neg. } \\
\hline & & & $\begin{array}{l}\text { anti-HBs: } \\
<100 \text { IU/L }\end{array}$ & $\begin{array}{l}\text { anti-HBs: } \\
>100 \mathrm{IU} / \mathrm{L}\end{array}$ \\
\hline Anti-CD20 or anthracyclin derivates & NA & NA & NA & $\mathrm{Obs}^{*}$ \\
\hline $\begin{array}{l}\text { Systemic corticosteroids } \geq 4 \text { weeks, } \\
\text { or anti-TNF-alpha, other cytokine, } \\
\text { integrin, or tyrosine kinase inhibitors }\end{array}$ & NA & NA & Obs1 & Obs1 \\
\hline Azathioprine, methotrexate & NA & Obs1 & Obs1 & Obs1 \\
\hline $\begin{array}{l}\text { Intra-articular corticosteroid or high } \\
\text { dose (> } 20 \mathrm{mg} / \text { die) of systemic } \\
\text { corticosteroid }<4 \text { weeks }\end{array}$ & Obs2 & Obs2 & NAR & NAR \\
\hline $\begin{array}{l}\text { Small or intermediate dose ( } \leq 20 \mathrm{mg} / \mathrm{die}) \\
\text { of systemic corticosteroid }<4 \text { weeks }\end{array}$ & Obs3 & Obs3 & NAR & NAR \\
\hline
\end{tabular}

NA: initiate ETC or TDF or TAF; Obs1 = ALT/GPT at weeks 2 and 4, thereafter monthly, and HBV DNA titer and/or anti-HBs in every three months; Obs2 = ALT/GPT on weeks 2 and 4, thereafter monthly for three months, and HBV DNA at month 3; Obs3 = ALT/GPT at weeks 2 and 4.

* Exception: NA therapy is recommended for onco-haematology patients who receive rituximab in mono- or combination therapy.

Abbreviations: NA = nucleot/side analogue; ETC = entecavir; TAF= tenofovir alafenamide fumarate; TDF = tenofovir disoproxil fumarate; Anti-CD20 = antibody to CD20; anti-TNF- $\alpha=$ antibody to tumor necrosis factor alpha; HBsAg = HBV surface antigen; anti-HBc = antibody to the HBV core antigen; anti-HBs = antibody to the HBV surface antigen; HBV = hepatitis B virus; DNA = dezoxyribonucleic acid; Obs = observation; NAR = no action required; $A$ LT/GPT = alanine transaminase 
Abbreviations

ADV $=$ adefovir

ALT/GPT = alanine transaminase

anti-HBC = antibody to the HBV core antigen

anti-HBe = antibody to the HBV e antigen

anti-HBs = antibody to the HBV surface antigen

anti-HD = antibody to the HDV

AST/GOT = aspartate aminotransferase

$\mathrm{CHB}=$ chronic viral hepatitis $\mathrm{B}$

$\mathrm{CHC}=$ chronic viral hepatitis $C$

$\mathrm{CHD}=$ chronic viral hepatitis $\mathrm{D}$

$\mathrm{CLD}=$ chronic liver disease

DNA = dezoxyribonucleic acid

$\mathrm{ETC}=$ entecavir

$F 0, F 1, F 2, F 3, F 4=$ stages of fibrosis

(Metavir score)

$\mathrm{HAI}=$ hepatitis activity index

HAV = hepatitis A virus

$\mathrm{HBsAg}=\mathrm{HBV}$ surface antigen

$\mathrm{HBeAg}=\mathrm{HBV}$ e antigen

$\mathrm{HBV}=$ hepatitis $B$ virus
$\mathrm{HCC}=$ hepatocellular carcinoma

$\mathrm{HCV}=$ hepatitis $\mathrm{C}$ virus

$\mathrm{HCW}=$ health care workers

$\mathrm{HDAg}=\mathrm{HDV}$ antigen

$H D V=$ hepatitis $D$ virus

IFN = interferon alpha

LAM = lamivudine

$\mathrm{LS}=$ liver stiffness

$\mathrm{NA}=$ nucleot/side analogue

NEAK = Nemzeti Egészségbiztosítási Alap Kezelő

(National Health Insurance Fund)

$\mathrm{PCR}=$ polymerase chain reaction

PEG-IFN = pegylated interferon alpha

RNA = ribonucleic acid

stdIFN = standard interferon

$\mathrm{TAF}=$ tenofovir alafenamide fumarate

TDF = tenofovir disoproxil fumarate

US = ultrasound examination

DAA = direct acting antiviral agents

OGYÉl = Országos Gyógyszerészeti és Élelmezés-

egészségügyi Intézet (National Institute of

Pharmacy and Nutrition) achieved, risk of complications is low, work-ability and lifeexpectancy are close to non-infected individuals. Effective therapies are basically available in Hungary. However, complete "cure" of HBV with registered therapies is nowadays not possible.

Early recognition and per guideline treatment of HBV infection require organized high-scale screening programs.
Without such programs, reduction of $\mathrm{HBV}$ incidence and related mortality goal set by WHO cannot be achieved in Hungary by 2030 .

\section{Acknowledgments}

We express our gratitude to Árpád Kiss (Satco Ltd) for his technical assistance in the preparation of this paper.

\section{Irodalom}

1. Horváth G, Gerlei Zs, Gervain J, et al. Diagnosis and treatment of chronic hepatitis $B$ and $D$. Hungarian national consensus guideline from 17 September 2017 (A B- és D-vírus hepatitis diagnosztikája, antivirális kezelése. Magyar konszenzusajánlás). Orv Hetil 2018; 159(Suppl 1): 24-37. 2. Hungarian Ministry of Human Resources. Management of chronic $B$ and $D$ hepatitis. Protocol for of the Hungarian Ministry of Human Resources (A Nemzeti Erőforrás Minisztérium Szakmai Protokollja a B- és D-hepatitis kezeléséről). Egészségügyi Közlöny 2011; 61(7): 1379-1385. www. kozlonyok.hu/kozlonyok/Kozlonyok/6/PDF/2011/7.pdf (Hungarian) 3. EASL 2017 Clinical Practice Guidelines on the management of hepatitis B virus infection. European Association for the Study of the Liver. $J$ Hepatol 2017; 67: 370-398.

4. Terrault NA, Lok SF, McMahon J, et al. Update on prevention, diagnosis and treatment of chronic hepatitis B AASLD 2018 Hepatitis B Guidance. Hepatology 2018; 67: 1560-1599.

5. Horváth G. New drugs for the treatment of chronic hepatitis $B$ and interdisciplinary aspects of chronic hepatitis $B$ virus infection (A hepatitis $B$ vírusfertőzés új gyógyszerei és interdiszciplináris vonatkozásai). Orv Heti 2013; 154: 1142-1150. (Hungarian)

6. Pár A, Pár G. Non-invasive fibrosis assessment in chronic hepatitis C: aspartate-aminotransferase to platelet ratio index (APRI) and transient elastography (FibroScan). (Nem invaziv fibrosisdiagnosztika kronikus C-hepatitisben: aszpartat-aminotranszferaz/ thrombocyta hanyadosindex (APRI) es tranziens elasztografia (FibroScan)). Orv Hetil 2010; 151: 1951-1955. (Hungarian)

7. Horváth G. New non-invasive tool for assessment of liver fibrosis: transient elastography. (A majfibrosis meghatarozasanak uj, noninvaziv modszere: tranziens elasztografia) (FibroScan). Orv Hetil 2011; 152: 860-865. (Hungarian)

8. Chen CJ, Yang HI, Su J, et al. Risk of hepatocellular carcinoma across a biological gradient of serum hepatitis B virus DNA level. JAMA 2006; 295: 65-73.

9. Marcellin P, Gane E, Buti M, et al. Regression of cirrhosis during treatment with tenofovir disoproxil fumarate for chronic hepatitis B: a 5-year open-label follow-up study. Lancet 2013; 381: 468-475.

10. Shim JH. Efficacy of entecavir in teratment-naive patients with he- patitis B virus-related decompensated cirrhosis. J. Hepatol 2010; 52 : 176-182.

11. Brouwer WP, Xie Q, Sonneveld MJ, et al. Adding pegylated interferon to entecavir for hepatitis $B$ e antigen positive chronic hepatitis B. A multicenter randomized trial (ARES study). Hepatology 2015; 61: 1512-1522. 12. Bzowej NH. Hepatitis B therapy in pregnancy. Curr Hepat Rep 2010; 9: 197-204.

13. Han GR, Cao MK, Zhao W, et al. A prospective and open-label study for the efficacy and safety of telbivudine in pregnancy for the prevention of perinatal transmission of hepatitis B virus infection. Br J Hepatol 2011; 55: 1215-1221.

14. Raimondo G, Pollicino T, Cacciola I, et al. Occult hepatitis B virus infection. J Hepatol 2007; 46: 160-170.

15. Evens AM, Jovanovic BD, Su YC, et al. Rituximab-associated hepatitis $B$ virus (HBV) reactivation in lymphoproliferative diseases: meta-analysis and examination of FDA safety reports. Ann Oncol 2011; 22: 1170-1180.

16. Lalazar G, Rund D, Shouval D. Screening, prevention and treatment of viral hepatitis $B$ reactivation in patients with haematological malignancies. Br J Haematol 2007; 136: 699-712.

17. Marzano A, Angelucci E, Andreone P, et al. Prophylaxis and treatment of hepatitis B in immunocompromised patients. Dig Liver Dis 2007; 39: 397-408.

18. Vigano M, Vener C, Lampertico $P$, et al. Risk of hepatitis B surface antigen seroreversion after allogeneic hematopoietic SCT. Bone Marrow Transplant 2011; 46: 125-131.

19. Lok ASF, Bonis PAL. Hepatitis B virus reactivation associated with immunosuppressive therapy. Available: http://www.uptodate.com/contents/hepatitis-b-virus-reactivation-associated-with-immunosuppressive-therapy.

20. Reddy KR, Beavers KL, Hammond SP, et al. New Guidelines for Managing Hepatitis B Reactivation During Immunosuppressive Therapy. Gastroenterology 2015; 148: 215-219. (available: http://www.medscape. com/viewarticle/843497).

21. Perillo PR, Gish R, Falk-Ytter YT. American Gastroenterological Association Institute Technical Review on Prevention and Treatment of Hepatitis B Reactivation During Immunosuppressive Drug Therapy. Gastroenterology 2015; 148: 221-244. (available: http://www.gastrojournal.org/ article/S0016-5085(14)01330-4/abstract) 